\title{
Sensitive Five-Fold Local Symmetry to Kinetic Energy of Depositing Atoms in Cu-Zr Thin Film Growth
}

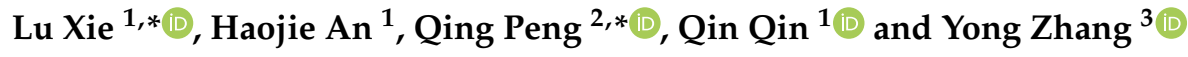 \\ 1 School of Mechanical Engineering, University of Science and Technology Beijing, Beijing 100083, China; \\ anhaojie@xs.ustb.edu.cn (H.A.); qinqin@me.ustb.edu.cn (Q.Q.) \\ 2 Nuclear Engineering and Radiological Sciences University of Michigan, Ann Arbor, MI 48108, USA \\ 3 State Key Laboratory for Advanced Metals and Materials, University of Science and Technology Beijing, \\ Beijing 100083, China; drzhangy@ustb.edu.cn \\ * Correspondence: xielu@ustb.edu.cn (L.X); qpeng.org@gmail.com (Q.P)
}

Received: 26 November 2018; Accepted: 12 December 2018; Published: 14 December 2018

\begin{abstract}
We have investigated the glass formation ability of $\mathrm{Cu}-\mathrm{Zr}$ alloy by molecular dynamics simulation of the deposition process. The atomistic structures of $\mathrm{Zr}_{x} \mathrm{Cu}_{100-x}$ metallic glass films have been systematically examined under the growth conditions of hypereutectic-eutectic, near-eutectic, and hypoeutectic regions by the radial distribution function and simulated $\mathrm{X}$-ray diffraction. The structure analysis using Voronoi polyhedron index method demonstrates the variations of short-range order and five-fold local symmetry in $\mathrm{Zr}_{x} \mathrm{Cu}_{100-x}$ metallic glass films with respect to the growth conditions. We manifest that the five-fold local symmetry is sensitive to the kinetic energy of the depositing atoms. There is positive correlation between the degree of five-fold local symmetry and glass forming ability. Our results suggest that sputtering conditions greatly affect the local atomic structures and consequential properties. The glass forming ability could be scaled by the degree of five-fold local symmetry. Our study might be useful in optimizing sputtering conditions in real experiments, as well as promising implications in material design of advanced glassy materials.
\end{abstract}

Keywords: molecular dynamics simulation; metallic glasses; glass forming ability; thin film growth; five-fold local symmetry

\section{Introduction}

A solid metal in general is a crystalline where atoms have long range orders. When they are quenched with ultra-high cooling rate from melt, they form amorphous metals, namely metal glasses (MGs). Unlike common glasses, metallic glasses are metals, and therefore good in electrical conductivity and thermal conductivity. Without long-range orders or translational symmetry in structure, metallic glasses in general possess much higher strength, hardness, and corrosion resistance than their crystalline counterparts [1-4]. As a result, MGs have attracted extensive interest due to their exotic mechanical properties and promising applications [5,6]. However, the poor glass-forming ability (GFA) limits the broad engineering application of MGs, which restricts both the shape and the size of MGs. The key to the design of MGs with great GFA is to understand the structural origin of GFA, which, however, is a long-standing challenge.

Metallic glasses are usually obtained by rapid cooling of multicomponent alloy that the crystallization is avoided. The binary $\mathrm{Zr}-\mathrm{Cu}$ alloy is a paradigm system to study the atomistic structures properties relationships and glass transition due to the outstanding glass formation ability which originated from the ideal atomic size ratio between the two constituents [7]. Recent studies have shown that binary $\mathrm{Zr}-\mathrm{Cu}$ alloys have the ability to form a variety of stable metallic glass with different atom ratios [8,9], and the amorphous film formed by $\mathrm{Zr}-\mathrm{Cu}$ alloys has prefect mechanical [10-12] and superconducting properties [13]. 
Currently, MGs thin films are mainly prepared by magnetron sputtering deposition method. There are lots of experiments and theoretical studies on this deposition process. For example, Dudonis et al. [14] performed electron bombardment of $\mathrm{Cu}$ and $\mathrm{Zr}$ targets at different powers to prepare different compositional $\mathrm{Zr}_{\mathrm{x}} \mathrm{Cu}_{100-\mathrm{x}}$ films $(5 \leq \mathrm{x} \leq 95)$ in a magnetron sputtering deposition. Apreutesei et al. [15] prepared $\mathrm{Zr}-\mathrm{Cu}$ MG films by DC magnetron sputtering in argon gas, and studied the influence of deposition parameters on structure and elastic properties. Daisman et al. [16] used single-target magnetron sputtering method to prepare Zr-based MG thin films with higher stability. $\mathrm{Xu}$ et al. [17] studied the correlation between GFA and mechanical behavior of $\mathrm{Zr}-\mathrm{Cu}$ MGs. It is intriguing to see if there exists a similar correlation between GFA and microstructure.

Besides experiments, the method of molecular dynamics simulations (MD simulation) has been well established in the past decades and becomes a reliable and indispensable tool in various investigations [18]. For MGs, Utz et al. [19] introduced an algorithm for plastic deformation of $\mathrm{A}_{80} \mathrm{~B}_{20}$ two-component metallic glasses, which allows the use of MD simulations to study the volume changes related to plastic deformation directly. Sha et al. [20] studied the medium/short-range order of $\mathrm{Zr}_{64} \mathrm{Cu}_{36} \mathrm{MG}$ by using MD method. The compressive mechanical properties of $\mathrm{Zr}_{85} \mathrm{Cu}_{15}$ nanocrystal-MG composites have been analyzed via MD simulations [21]. Yang et al. [22] studied the size effects in $\mathrm{Zr}_{50} \mathrm{Cu}_{50} \mathrm{MG}$ films via MD simulations. In our previous work [23], we use the MD method to simulate the deposition process of $\mathrm{Zr}_{x} \mathrm{Cu}_{100-x}$ metallic glass film and investigated the effect of different element ratios.

The microstructure and glass forming mechanism are among the main important topics of MD studies. Sha et al. [20,24] studied the forming conditions of $\mathrm{Zr}-\mathrm{Cu}$ MGs by using MD simulation. Hajlaoui et al. [25] observed the microstructure of $\mathrm{Zr}$-Cu MGs during deformation by in-situ HRTEM observation. The studies from Almyras et al. [26] show that both $\mathrm{Zr}_{35} \mathrm{Cu}_{65}$ and $\mathrm{Zr}_{65} \mathrm{Cu}_{35} \mathrm{MGs}$ are composed of supercluster formed by icosahedral-like clusters. Tripathi et al. [27] proposed a glass forming ability expression that does not use the characteristic temperature, which analyzes the GFA of the alloy from the component data. Turchanin et al. [28] considered that the interaction between components is an important reason for amorphization of alloy through the study of enthalpy of $\mathrm{Zr}-\mathrm{Cu}$ system. The theory proposed by Zhang et al. [29] claims that the formation of the microstructure of the multi-alloy has a direct relationship with the property parameters $\Omega$ and $\delta(\Omega$ is the ratio of average melting temperature timing the mixing entropy and the mixing enthalpy, and $\delta$ is the mean square deviation of the atomic size), which can be used to predict whether the alloy can form metallic glass. It was reported that five-fold local symmetry (FFLS) is an important characteristic in MGs. Hu et al. [30] studied the structure evolution in metallic glass-forming liquids by FFLS. Lu et al. [31] studied the correlation between FFLS and dynamical slowing down in $\mathrm{Cu}-\mathrm{Zr}$ glass-forming liquid, and results show that FFLS has a close relation to GFA.

For the $\mathrm{Zr}-\mathrm{Cu}$ system, there are few studies on its crystal-amorphous transition and the relationship between microstructure and GFA, while current research only involves the deposition process and the mechanical properties of the metal film. The metallic glass transition mechanism remains elusive. With the well-established molecular dynamics simulations, we can accurately simulate the deposition process of $\mathrm{Zr}-\mathrm{Cu}$ alloy thin films and explore the film evolution process at the atomic level. Therefore, MD method is employed in this study. We simulate the deposition process of amorphous films of $\mathrm{Zr}_{x} \mathrm{Cu}_{100-x}(\mathrm{x}=50,70,90)$ in sub-eutectic, near-eutectic, and hypoeutectic regions. The crystal-amorphous transition has been studied in depth. Its glass forming mechanism and the relationship between microstructure and GFA have been analyzed upon these simulations.

\section{Models and Methods}

All MD simulations in this work were performed using the Large-scale Atomic/Molecular Massively Parallel Simulator (LAMMPS) package (Sandia, Albuquerque, NM, USA) [32]. The structural analysis and post-processing were performed with OVITO [33]. 


\subsection{Modeling}

Figure 1 shows the initial deposition model used in this work. Each simulation box has periodic boundary conditions only in $\mathrm{x}$ and $\mathrm{y}$ directions. Si $\left(\begin{array}{lll}1 & 0 & 0\end{array}\right)$ with fixed bottom atoms was used as the substrate and the dimensions were $(25 \times 25 \times 10) \AA^{3}$. In the deposited process, two kind of deposited atoms were generated randomly. Both $\mathrm{Zr}$ and $\mathrm{Cu}$ atoms deposited from an initial position 5-7 $\AA$ above the deposition model.

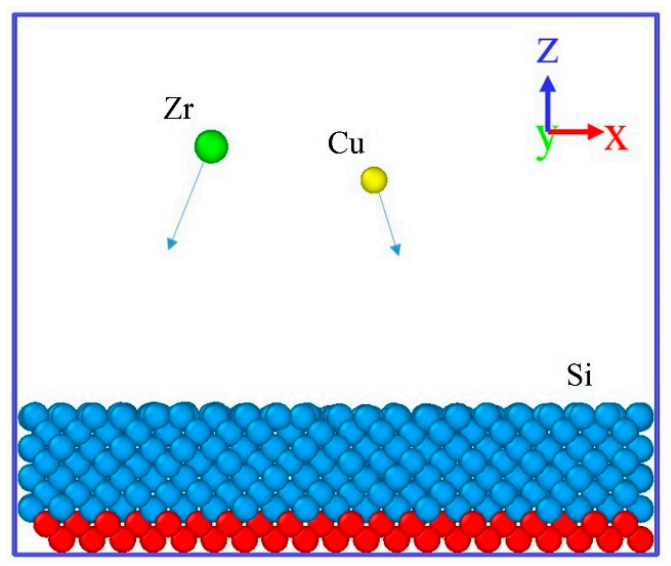

Figure 1. Schematic picture of the deposition model. Green atom is $\mathrm{Zr}$, yellow atom is $\mathrm{Cu}$, blue and red atoms are moving and fixed $\mathrm{Si}$, respectively. The simulation box is periodic in the $\mathrm{x}$ and $\mathrm{y}$ directions. (In order to facilitate the display of nanostructures, the atom radius in the figure does not represent the actual atomic size, the same below).

For all simulations, the microcanonical ensemble (NVE) was employed with a Berendsen thermostat [34]. Berendsen thermostat can effectively dissipate the high energy coming from $\mathrm{Zr}-\mathrm{Cu}$ atoms. The temperature of the simulation box was controlled to $300 \mathrm{~K}$, which is similar to experimental temperature condition.

In these simulations, embedded atom method (EAM) many-body potential [35] was applied to describe the atomic interactions of the $\mathrm{Zr}-\mathrm{Cu}$ systems. The interactions between $\mathrm{Si}$ and $\mathrm{Si}$ atoms were described by Tersoff empirical potential [36]. Lennard Jones potential with Lorenz Berthelot mixing rules [37] was employed for the atomic interactions between $\mathrm{Si}$ and $\mathrm{Zr}-\mathrm{Cu}$ systems.

\subsection{Simulation Process}

We use the modified Thompson formula (detailed in Supplementary) to calculate the mean kinetic energy [38] of the incoming $\mathrm{Zr}$ and $\mathrm{Cu}$ atoms. We examine three different experimental conditions (Table 1). The velocities of the incoming atoms are randomly sampled from a Maxwell Boltzmann distribution. The aim is to simulate the three different conditions in metallic glass growth, and to gain insights of the effect of both the incoming atom kinetic energy and the composition on the expected phase formation of $\mathrm{Zr}-\mathrm{Cu}$ system.

Table 1. The calculated mean kinetic energy for depositions.

\begin{tabular}{ccc}
\hline Sample of Mean Kinetic Energy & $\mathrm{Zr}(\mathrm{eV})$ & $\mathbf{C u}(\mathbf{e V})$ \\
\hline (a) Low energy group & 0.13 & 0.34 \\
(b) Middle energy group & 7.65 & 6.67 \\
(c) High energy group & 12.6 & 9.61 \\
\hline
\end{tabular}

The deposited atoms are randomly generated. The initial velocity and direction are given to make them continuously deposited to the substrate. The time step is chosen to be $0.001 \mathrm{ps}$ for the compromise of computation speed and numerical instability. Every 2 ps, 5 atom are released toward 
the surface. This rate of 0.5 atom/ps is carefully selected so that there is enough time for thermal relaxation to take place with Berendsen thermostat.

For post-simulation analysis, we use the radial distribution functions (RDF) to determine the correlation between the atoms. The simulated X-ray diffraction (XRD) was employed to study the phase of $\mathrm{Zr}-\mathrm{Cu}$ film and the Voronoi polyhedron index method (VPIM) [39] was employed to analyze the local atomic structure and FFLS of the system.

\section{Results and Discussion}

In order to study the deposition process and structural evolution of $\mathrm{Zr}-\mathrm{Cu}$ alloy, $\mathrm{MD}$ simulations of the growth of $\mathrm{Zr}_{x} \mathrm{Cu}_{100-x}$ alloy and $\mathrm{x}$ is percentage of the atomic concentrations. We investigate $x=50,70,90$, which is response to the sub-eutectic, near-eutectic, and hypoeutectic composition, respectively. The growth of the alloys was performed in three different energies, as listed in Table 1 , with initial conditions similar to the experimental operating ones.

\section{1. $\mathrm{Zr}_{50} \mathrm{C} u_{50}$}

The $\mathrm{Zr}_{50} \mathrm{Cu}_{50}$ deposition processes with different conditions on the Si substrate are shown in Figure 2. The results show that as the mean kinetic energies increases, the morphology goes through three different stages: cluster-film-film. For $\mathrm{Zr}_{50} \mathrm{Cu}_{50}$ the $\mathrm{Zr}$ and $\mathrm{Cu}$ atoms grow as a cluster with height $7.0 \mathrm{~nm}$ under low energy. Under middle and high energies, the deposited atoms grow as clusters before $5 \mathrm{~ns}$. Finally, two $5.5 \mathrm{~nm}$ thickness films were formed at middle and high energies. The mean kinetic energy of the deposited atoms is relatively lower at low energy $\left(\mathrm{E}_{\mathrm{Zr}}=0.13 \mathrm{eV}\right.$, $\mathrm{E}_{\mathrm{Cu}}=0.34 \mathrm{eV}$ ), which is less than the activation energy for atomic diffusion. Therefore, the atoms are easier to aggregate with each other to form clusters.

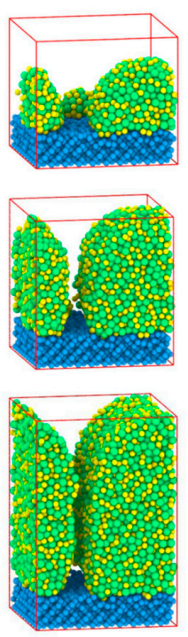

(a) low
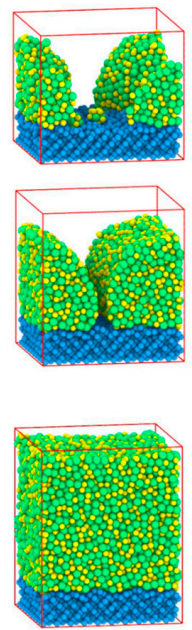

(b) middle

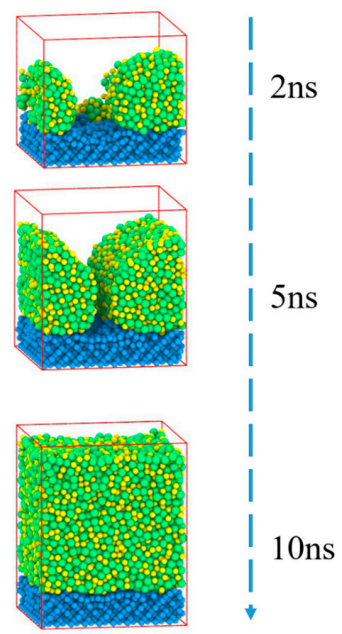

(c) high

Figure 2. Snapshots of $\mathrm{Zr}_{50} \mathrm{Cu}_{50}$ deposited on Si substrate at 2 ns, 5 ns and 10 ns under different energies. The (a), (b), and (c) show the deposition process under three different energies, and the films grew to approximately $7.0 \mathrm{~nm}, 5.5 \mathrm{~nm}$, and $5.5 \mathrm{~nm}$ thickness respectively.

The total RDFs for $\mathrm{Zr}_{50} \mathrm{Cu}_{50}$ under three energies are presented in Figure 3a. For MGs, the RDF peak positions are the inherited characteristic constant sequence [40] and the peaks show the nearest neighbor distance of atoms, which can be compared with the experimental values of the two elementals (Supplementary Table S1). The RDF shows an asymmetrical first peak and a second peak with no spilt in three energies, implying that there exists a strong short-range order. While the shoulder peak on the right side of the first peak in deposited $\mathrm{Zr}_{50} \mathrm{Cu}_{50}$ films are not observed as literature [41]. The three energies in our simulations show that the RDF distributions are similar, and no effect of the mean kinetic energy is observed for $\mathrm{Zr}_{50} \mathrm{Cu}_{50}$. 

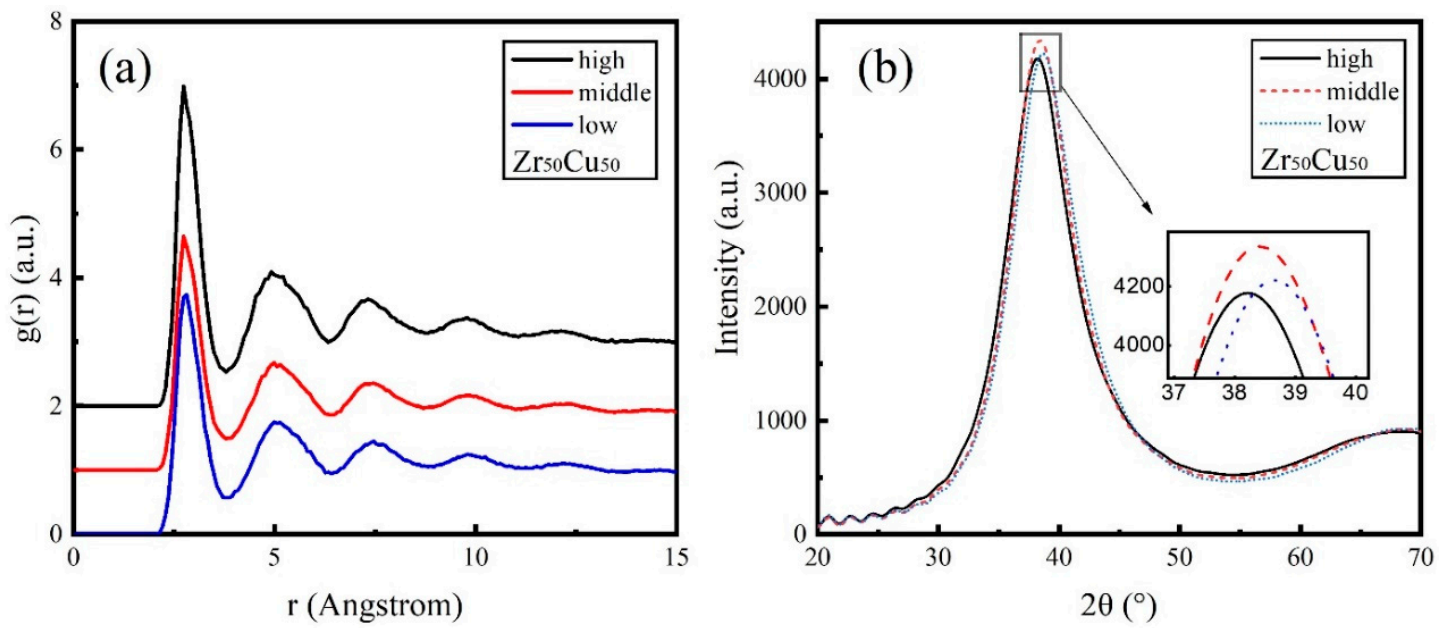

Figure 3. Simulated deposition of $\mathrm{Zr}_{50} \mathrm{Cu}_{50}$ thin films. (a) Radial distribution function $\mathrm{g}(\mathrm{r})$ of deposited alloy film under different energies, and the abscissa indicates atomic distance $r$; (b) the relationship between $X$-ray diffraction intensity and diffraction angle $2 \theta$ of deposited alloy film under different energies.

The $\mathrm{XRD}$ patterns for $\mathrm{Zr}_{50} \mathrm{Cu}_{50}$ are illustrated in Figure $3 \mathrm{~b}$ as a function of the mean kinetic energy. All of these patterns show broad diffraction peaks without any detectable sharp Bragg peaks, implying a low order structure. $\mathrm{Zr}_{50} \mathrm{Cu}_{50}$ films show an amorphous $\mathrm{XRD}$ pattern which is consistent with the calculated RDF in Figure 3a. As the mean kinetic energies increases, the value of the first peak in the $X R D$ pattern gradually decreases. The diffraction angles of the first XRD peaks for $\mathrm{Zr}_{50} \mathrm{Cu}_{50}$ under three energies are between 38 and 39 degrees.

\section{2. $\mathrm{Zr}_{70} \mathrm{Cu} 30$}

Deposition processes of $\mathrm{Zr}_{70} \mathrm{Cu}_{30}$ on $\mathrm{Si}\left(\begin{array}{ll}1 & 0\end{array}\right)$ at $2 \mathrm{~ns}, 5 \mathrm{~ns}$ and $10 \mathrm{~ns}$ under three different energies are presented in Figure 4. Initially, small nanoclusters formed on the $\operatorname{Si}\left(\begin{array}{lll}1 & 0 & 0\end{array}\right)$ surface and formed thin films gradually as the number of incoming atoms increases. One can see from Figure 4 that as increasing the mean kinetic energies, the morphology goes through three stages: cluster-cluster-film at $5 \mathrm{~ns}$. At high energy, the thin film was formed before the other two energies. Finally, $\mathrm{Zr}_{70} \mathrm{Cu}_{30}$ films have been formed with thickness ranging from 6.0 to $6.4 \mathrm{~nm}$.

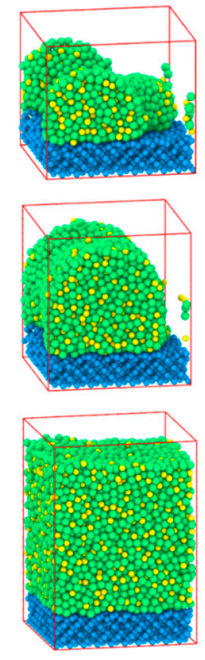

(a) low
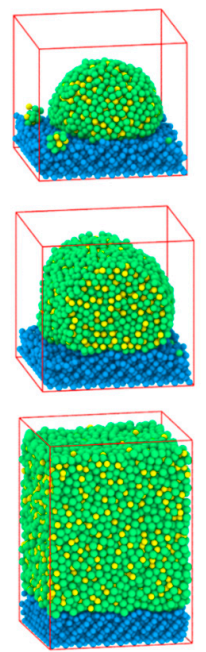

(b) middle

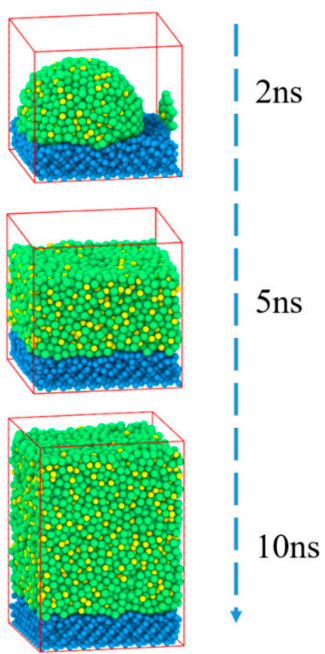

(c) high

Figure 4. Snapshots of $\mathrm{Zr}_{70} \mathrm{Cu}_{30}$ deposited on Si substrate at 2 ns, 5 ns and 10 ns under different energies. The (a), (b), and (c) show the deposition process under three different energies, and the films grew to approximately $6.0 \mathrm{~nm}, 6.4 \mathrm{~nm}$, and $6.2 \mathrm{~nm}$ thickness respectively. 
The total RDF distributions of $\mathrm{Zr}_{70} \mathrm{Cu}_{30}$ deposited films are displayed in Figure 5 for three deposition energies. The first and second peaks broaden with no splits which shows a typical amorphous characteristic. The amorphous nature of $\mathrm{Zr}_{70} \mathrm{Cu}_{30}$ films under three energies is clearly shown in the snapshots presented in Figure 4, which means the near-eutectic alloy $\mathrm{Zr}_{70} \mathrm{Cu}_{30}$ has a strong GFA.
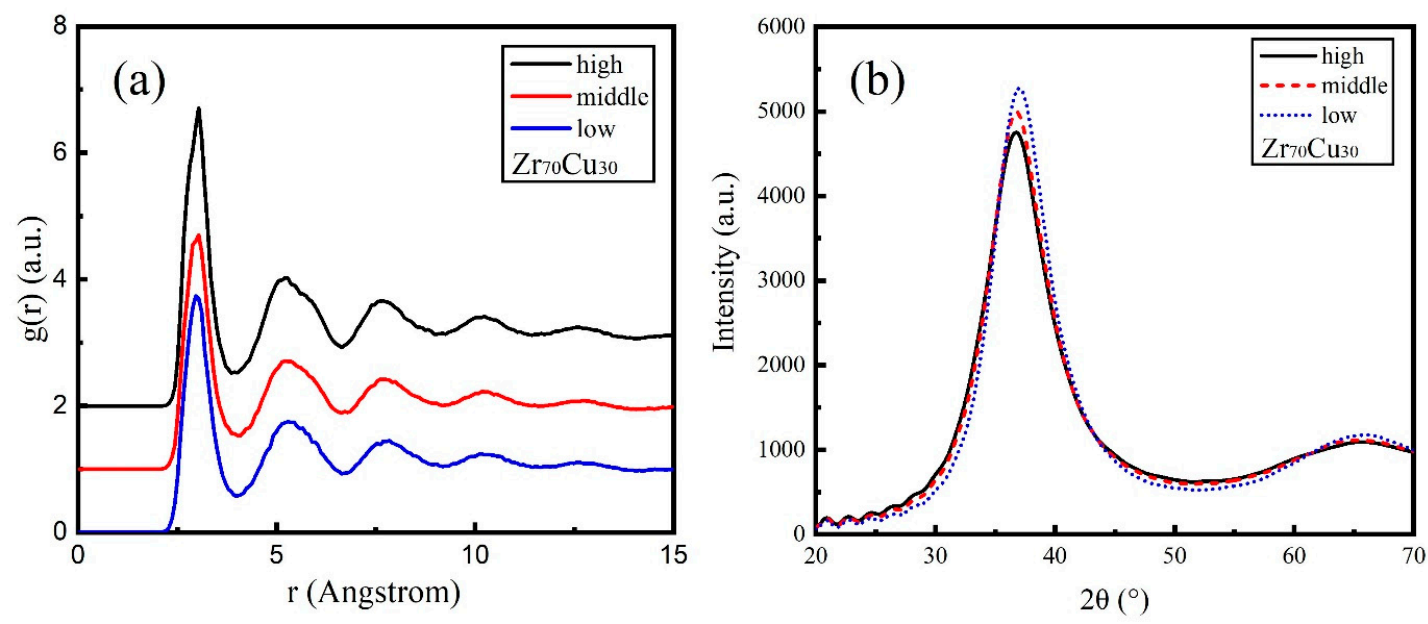

Figure 5. Simulated deposition of $\mathrm{Zr}_{70} \mathrm{Cu}_{30}$ thin films. (a) Radial distribution function $\mathrm{g}(\mathrm{r})$ of deposited alloy film under different energy conditions, and the abscissa indicates atomic distance $r$; (b) the relationship between $X$-ray diffraction intensity and diffraction angle $2 \theta$ of deposited alloy film under different energy conditions.

The simulated XRD intensities versus diffraction angle $2 \theta$ for $\mathrm{Zr}_{70} \mathrm{Cu}_{30}$ are illustrated in Figure $5 \mathrm{~b}$. Broad diffraction peaks with no split show an amorphous $\mathrm{Zr}_{70} \mathrm{Cu}_{30}$ structure. As the mean kinetic energies increases, the first peak decreases successively and the corresponding diffraction angle $2 \theta$ decreases. The main peak diffraction angles for $\mathrm{Zr}_{70} \mathrm{Cu}_{30}$ under three energies are around 37 degrees.

\section{3. $\mathrm{Zr}_{90} \mathrm{Cu} u_{10}$}

The deposition processes of the $\mathrm{Zr}_{90} \mathrm{Cu}_{10}$ are displayed in Figure $6 . \mathrm{Zr}_{90} \mathrm{Cu}_{10}$ is deposited as a cluster at $5 \mathrm{~ns}$ under low energy, and a film is formed with thickness about $7.1 \mathrm{~nm}$ at the end. Under middle and high energies, the deposited atoms grow as films with height around $7.0 \mathrm{~nm}$.

The $\mathrm{RDF}$ of $\mathrm{Zr}_{90} \mathrm{Cu}_{10}$ under three energies was calculated and is plotted in Figure 7a. For $\mathrm{Zr}_{90} \mathrm{Cu}_{10}$ deposition RDF, four distinct main peaks with a split of second peak arise, showing the well-crystallized structure. The crystallinity under the low energy was better than that of the other two energies according to the peak size and the split degree of second peak, that means the $\mathrm{Zr}_{90} \mathrm{Cu}_{10}$ deposited film shows a better crystal structure under the low energy.

The relationship between XRD intensity and diffraction angle $2 \theta$ of $\mathrm{Zr}_{90} \mathrm{Cu}_{10}$ alloy films is presented in Figure $7 \mathrm{~b}$ for different deposition energies. The XRD patterns exhibit three main peaks at all three cases, and the second peak at the middle energy shows a split. The position of the main XRD peak for $\mathrm{Zr}_{90} \mathrm{Cu}_{10}$ under three energies are between 35 and 36 degrees. Similar to the RDF pattern, the XRD pattern also shows that the three $\mathrm{Zr}_{90} \mathrm{Cu}_{10}$ alloy films have a perfect crystal structure. Among them, the peak of XRD pattern under low energy is bigger, but overall, the difference of XRD pattern under three conditions is not obvious. 


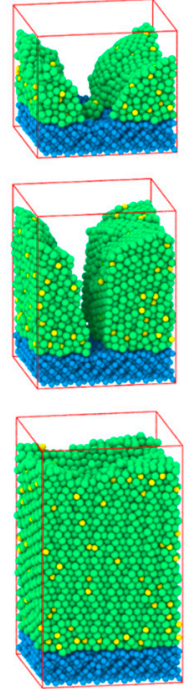

(a) low

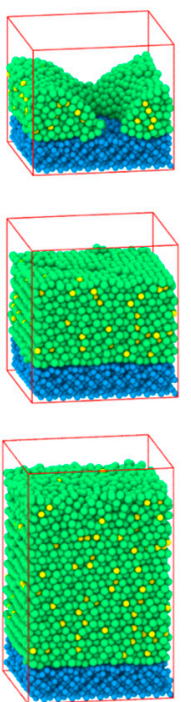

(b) middle

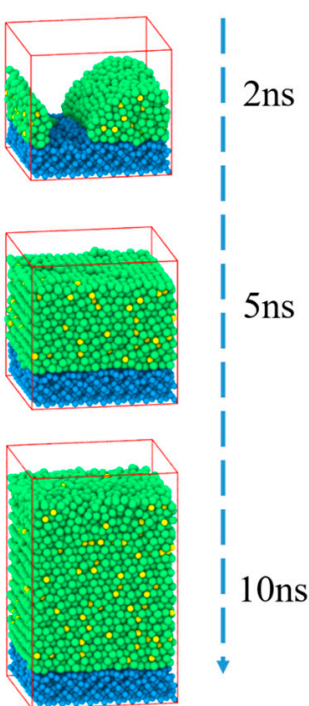

(c) high

Figure 6. Snapshots of $\mathrm{Zr}_{90} \mathrm{Cu}_{10}$ deposited on Si substrate at 2 ns, 5 ns and 10 ns under different energies. The (a), (b), and (c) show the deposition process under three different energies, and the films grew to approximately $7.1 \mathrm{~nm}, 7.0 \mathrm{~nm}$, and $7.0 \mathrm{~nm}$ thickness respectively.
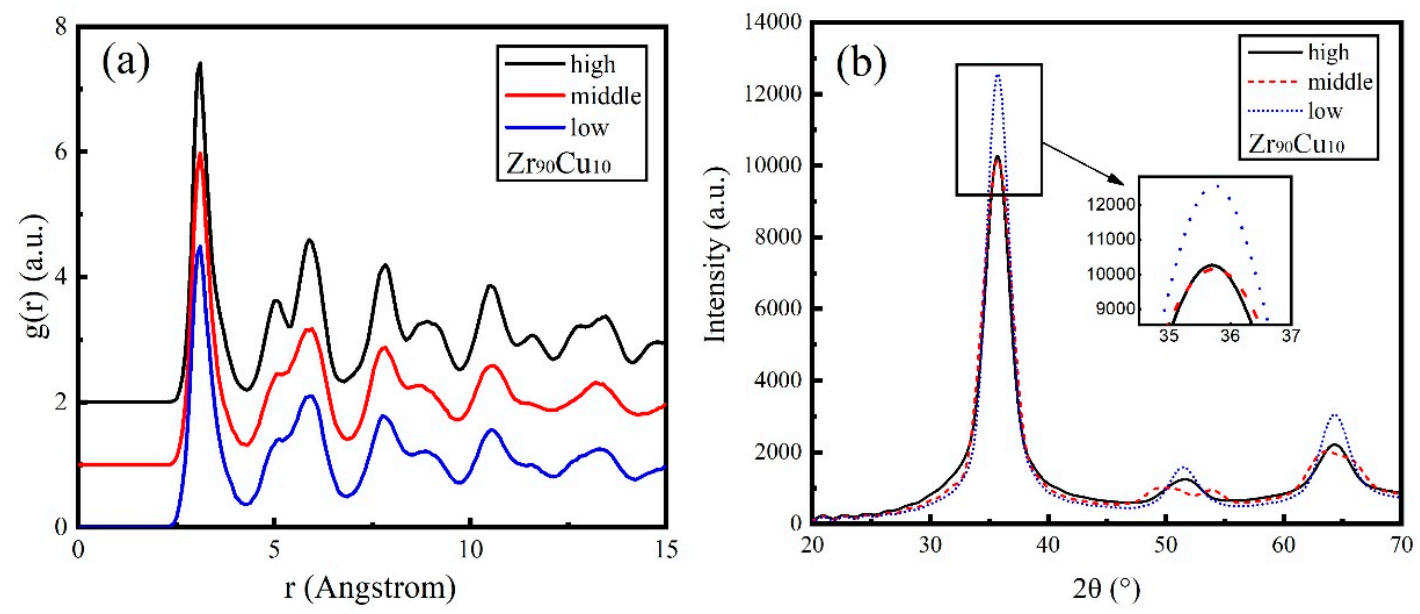

Figure 7. Simulated deposition of $\mathrm{Zr}_{90} \mathrm{Cu}_{10}$ thin films. (a) Radial distribution function $\mathrm{g}(\mathrm{r})$ of deposited alloy film under different energy conditions, and the abscissa indicates atomic distance $r$; (b) the relationship between $X$-ray diffraction intensity and diffraction angle $2 \theta$ of deposited alloy film under different energy conditions.

For deeper understanding of the film growth mechanism, snapshots of $\mathrm{Zr}_{90} \mathrm{Cu}_{10}$ deposited films under different energies are shown in Figure 8. The deposited film is a polycrystalline structure with both $A$ and B crystal orientations under low energy (Figure 8a). At the beginning of the deposition process, small clusters are formed with a random orientation distribution. With time goes on the film growth rates is almost the same, but the growth directions are different under different kinetic energies. This is because that the mean kinetic energy of the deposited atoms is less than the activation energy used for diffusion under low energy, thus forming two cluster structures with different growth directions. Nanostructures with different lattice orientations were formed as the deposition proceeds, that shows that the alloy thin film can be controlled toward a predetermined single crystal or poly-crystal direction by changing the energy condition of $\mathrm{Zr}_{90} \mathrm{Cu}_{10}$. The deposited film has a single crystal structure under middle energy (Figure $8 b$ ). While Figure $8 c$ shows a crystalline structure on the bottom and an amorphous structure on the top. The thickness of the amorphous structure is about $1.5 \mathrm{~nm}$. 


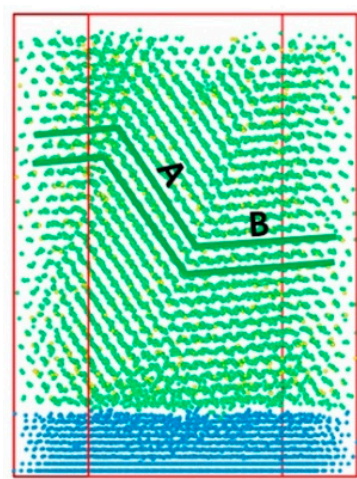

(a) low

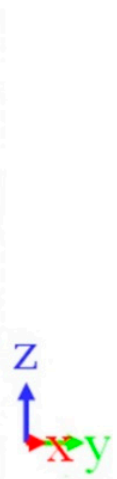

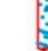

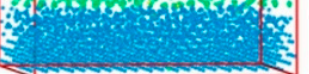

(b) middle

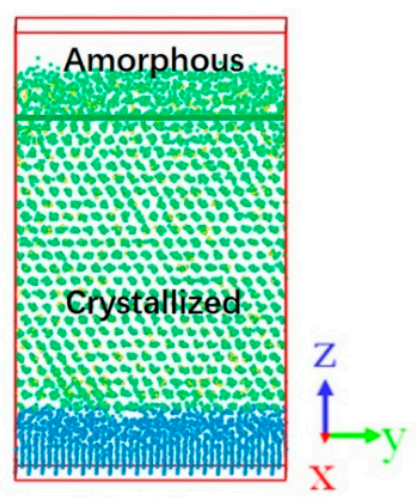

(c) high

Figure 8. Snapshots of $\mathrm{Zr}_{90} \mathrm{Cu}_{10}$ deposited at three energies. (a) The deposited film is a polycrystalline structure with both A and B crystal lattice orientations under low energy conditions; (b) the deposited film is a single crystal structure under middle energy conditions; (c) the deposited film exhibits a crystal-amorphous structure under high energy conditions.; the green solid line in (c) separate the crystalline and amorphous zones.

Based on these simulations, the thickness of films increases when increasing $\mathrm{Zr}$ concentrations. This caused by the difference of atomic radius, since the radius of $\mathrm{Zr}$ atoms is larger than that of $\mathrm{Cu}$ atoms. Comparing the RDF and XRD patterns of $\mathrm{Zr}_{x} \mathrm{Cu}_{100-x}(\mathrm{x}=50,70,90)$ deposited films under three energies, it is easy to find that the impact of the elemental composition is bigger than deposition conditions (mean kinetic energy) for GFA of $\mathrm{Zr}-\mathrm{Cu}$ system. Meanwhile, $\mathrm{Zr}_{50} \mathrm{Cu}_{50}$ and $\mathrm{Zr}_{70} \mathrm{Cu}_{30}$ have stronger ability to form metallic glass, while $\mathrm{Zr}_{90} \mathrm{Cu}_{10}$ tends to form crystalline structure and high energy is good for forming thin films.

\subsection{Glass Forming Ability}

The GFA of an alloy is related to manufacturing conditions and to its own structure properties [27]. The solid-solution formation rules are applicable to characterize the collective behavior of different elements in alloys [29,42]. The parameters $\Omega$ and $\delta$ of $\mathrm{Zr}_{x} \mathrm{Cu}_{100-x}$ defined for MD simulation are $\mathrm{Zr}_{90} \mathrm{Cu}_{10}(0.6686,6.12 \%), \mathrm{Zr}_{80} \mathrm{Cu}_{20}(0.5572,8.33 \%), \mathrm{Zr}_{70} \mathrm{Cu}_{30}(0.4981,9.75 \%), \mathrm{Zr}_{60} \mathrm{Cu}_{40}(0.4607,10.65 \%)$ and $\mathrm{Zr}_{50} \mathrm{Cu}_{50}(0.4363,11.11 \%)$, respectively [38].

In the relationship diagram of the $\Omega$ and $\delta$ (Figure 9), $\mathrm{Zr}-\mathrm{Cu}$ alloys are located in the area for bulk metallic glass (B). Meanwhile, the $\Omega$ and $\delta$ values of $Z_{50} C u_{50}$ and $Z_{70} C u_{30}$ correspond to the central of BMGs, indicating a strong amorphous forming ability. As increasing the $\mathrm{Zr}$ concentration, alloys trend to enter the area of BMGs to solid-solutions. This is consistent with the results of our simulations, that the system prefers to form crystalline structure with high concentration of $\mathrm{Zr}$. For $\mathrm{Zr}_{90} \mathrm{Cu}_{10}$, the thin film structure of polycrystalline, single crystal and crystalline-amorphous composite layer were obtained under low, middle and high energy conditions, which shows that the alloy with high $\mathrm{Zr}$ concentration is less likely to form metallic glass under the deposition. $\mathrm{Zr}_{90} \mathrm{Cu}_{10}$ located at the edge of the $\mathrm{B}$ area, that is closer to the area of solid-solutions (S) than the others. That theoretically explains our simulation results well. 


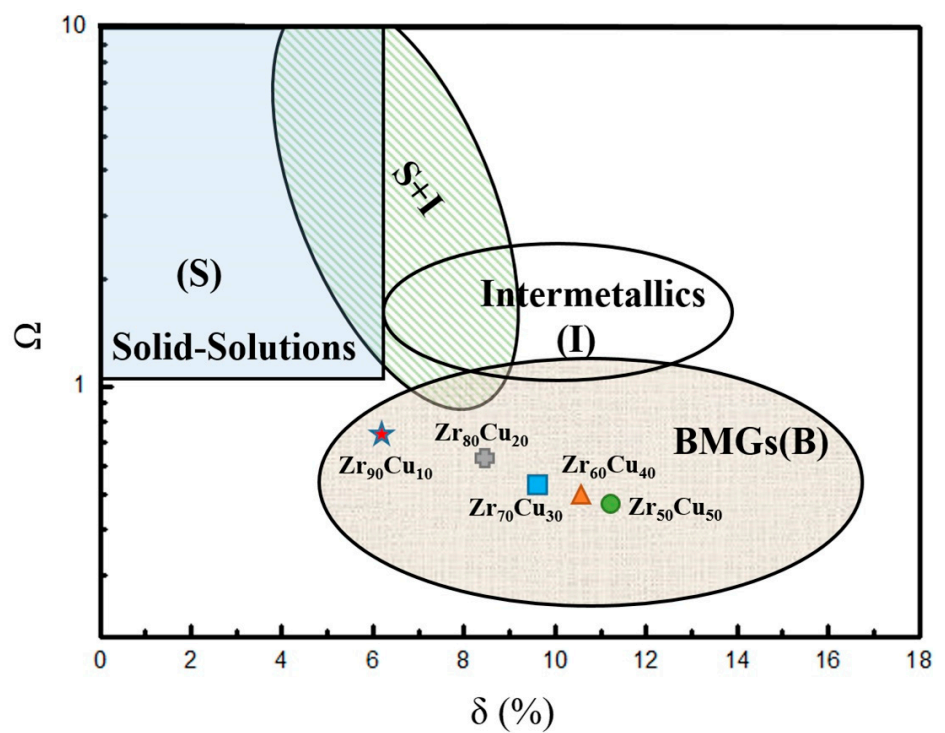

Figure 9. The prediction of phase formation for alloys. The region (S) shows that the alloy can form a solid solution. The alloy in the region (I) mainly consists of intermetallic compounds. The region (S+I) indicate that the solid solution and the intermetallic compound coexist, and alloy forms an amorphous phase metallic glass at the region (B) for bulk metal glasses (BMGs). $\Omega$ is the ratio of the average melting temperature timing the mixing entropy and the mixing enthalpy, and $\delta$ is the mean square deviation of the atomic size (reproduced from reference [29]).

Three groups of MD simulations revealed the formation of metallic glass microscopically, and the relationship between GFA and parameters $(\Omega$ and $\delta)$ values. The simulation results which confirmed the correctness of the theory and demonstrated the reliability of MD simulation, is of great significance to predict the thin film structure using magnetron sputtering deposition in MD simulation.

\subsection{Five-Fold Local Symmetry Analysis.}

To gain insights on the GFA at atomic level, we do more atomic structural analysis. The amorphous structure of $\mathrm{Zr}-\mathrm{Cu}$ alloys thin film was characterized by FFLS, which is one of the most popular methods to describe the nanostructure characteristics of MGs [43,44]. Different atomic clusters may contain different degree of FFLS, which can be expressed by $f_{i}^{k}=\left.n_{i}^{k}\right|_{k=3,4,5,6} n_{i}^{k}$, where $n_{i}^{k}(k=3,4,5,6)$ is the number of $k$-edged polygon in Voronoi polyhedron type $i$. And the average degree of $k$-fold local symmetry can be expressed by $\sum_{i} f_{i}^{k} \times P_{i}$, where $P_{i}$ is the fraction of $i$. Thus, the degree of FFLS for a polyhedron type can be expressed by $f_{i}^{5}=\left.n_{i}^{5}\right|_{k=3,4,5,6} n_{i}^{k}$ and the average degree of FFLS can be expressed by $W=\sum_{i} f_{i}^{k} \times P_{i}$.

The typical Voronoi polyhedrons (VPs) with three components are calculated and shown in Table S2 and Figure S1 in the supplementary information. According to the above-mentioned formula about FFLS, we calculate the average degree of FFLS. Solid line in Figure 10 shows the component dependence of the average degree of FFLS, which is denoted as W) under different energies obtained in MD simulations. With increasing $\mathrm{Zr}$ concentrations, $\mathrm{W}$ decreases gradually. The $\mathrm{W}$ of the first four components ( $x=50,60,70$ and 80$)$ are at a relatively high level, especially for $\mathrm{Zr}_{50} \mathrm{Cu}_{50} . \mathrm{Zr}_{50} \mathrm{Cu}_{50}$ has the strongest GFA and the largest $\mathrm{W}$ value, and exhibits perfect amorphous structure in our simulations. 


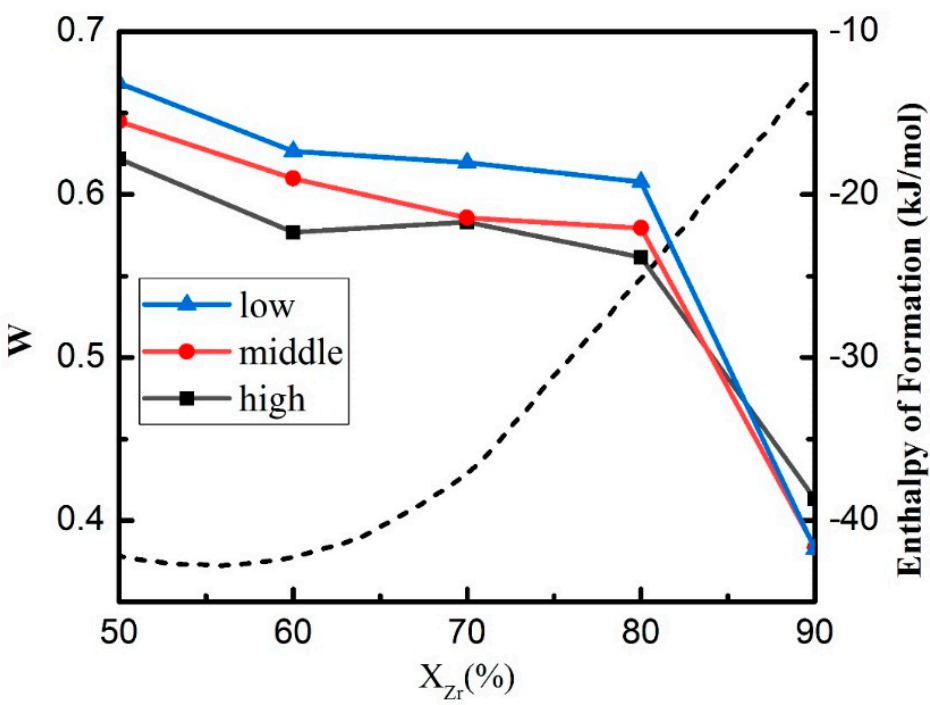

Figure 10. The evolution of five-fold local symmetry in $\mathrm{Zr}_{x} \mathrm{Cu}_{100-\mathrm{x}} . \mathrm{W}$ is the average degree of five-fold local symmetry (FFLS). The component dependence of $\mathrm{W}$ in different energy conditions shows similar trend. The dash line is the formation enthalpy of $\mathrm{Zr}-\mathrm{Cu}$ amorphous alloys from pure amorphous elements at the temperature of $298 \mathrm{~K}$ (reproduced from Turchanin [28]).

As shown in Figure 10, the increase of FFLS with decreasing the mean kinetic energy of incoming atoms indicates that FFLS shows energy dependence expect for $\mathrm{Zr}_{90} \mathrm{Cu}_{10}$. The largest $\mathrm{W}$ value occurs at the lowest energy shows that reducing the mean kinetic energy of incoming atoms will increase the five-fold local symmetry of the amorphous alloy. The GFA of $\mathrm{Zr}_{90} \mathrm{Cu}_{10}$ is the smallest, and the decrease of $\mathrm{W}$ is the most obvious. The difference between $\mathrm{Zr}_{90} \mathrm{Cu}_{10}$ and $\mathrm{Zr}_{\mathrm{x}} \mathrm{Cu}_{100-\mathrm{x}}(\mathrm{x}=50,60,70$ and 80 ) is that the maximum $\mathrm{W}$ of $\mathrm{Zr}_{90} \mathrm{Cu}_{10}$ appears in high energy conditions. This may be because of the well crystal characteristic exhibited in $\mathrm{Zr}_{90} \mathrm{Cu}_{10}$, and the disorder layer of $1.5 \mathrm{~nm}$ appearing on the surface of the film at high energy. At the same time, it shows that the FFLS is not suitable for the description of the long-range order structure.

The component dependence of the formation enthalpy of $\mathrm{Zr}-\mathrm{Cu}$ amorphous at $298 \mathrm{~K}$ is shown in the dash line (Figure 10) [28]. It can be seen that the amorphous formation enthalpy of the $\mathrm{Zr}-\mathrm{Cu}$ alloy is negative, and the enthalpy of the amorphous formation increases with the increase of $\mathrm{Zr}$ concentration when the $\mathrm{Zr}$ concentration is greater than $50 \%$. As the value of $\mathrm{x}$ increases, its GFA decreases, which is consistent with our simulation result.

Nearly eutectic $\mathrm{Zr}_{70} \mathrm{Cu}_{30}$ films deposited at three energy conditions have amorphous structures shown in our simulations. Combined with its FFLS and Voronoi polyhedral index, it is easy to find that the deposited film has better five-fold local symmetry and the highest content of icosahedron-like clusters under low energy, most of which are $\mathrm{Cu}$-centered. At the same time, using the average degree of FFLS, it is understandable that under low energy the deposited atoms formed film firstly at $5 \mathrm{~ns}$ (Figure 4), because it has largest degree of FFLS. On the other hand, as shown in Figure 9, the GFA of five alloys decrease with increasing $x$, which is coincident with the variation of the five-fold local symmetry that decrease with the $x$. Our results demonstrate that there is a positive correlation between GFA and the degree of FFLS of Zr-Cu systems.

\section{Conclusions}

We have investigated the correlation between the glass forming ability and the degree of the FFLS in the deposition process of $\mathrm{Zr}_{\mathrm{x}} \mathrm{Cu}_{100-\mathrm{x}}(\mathrm{x}=50,70,90)$ alloy thin films via molecular dynamics simulations. The structural state of alloy films was analyzed by RDF, XRD, Voronoi polyhedron index and FFLS. We find that $\mathrm{Zr}_{90} \mathrm{Cu}_{10}$ films all formed crystals under different energy deposition conditions. There are polycrystalline structure with two crystal orientations under low energy, single crystal under 
middle energy, and a crystalline-amorphous composite structure under high energy. The formation of crystalline-amorphous structure in $\mathrm{Zr}_{90} \mathrm{Cu}_{10}$ indicates that alloys located at the edge of area $\mathrm{B}$ can be prepared into a crystalline-amorphous composite by magnetron sputtering under certain conditions.

The Voronoi polyhedron analysis shows that the greater the number of icosahedral clusters and their deformed structures, the greater the GFA. The Voronoi polyhedron has an important influence on the GFA of $\mathrm{Zr}-\mathrm{Cu}$ system, and also reveals the relationship between composition and GFA. There is a positive correlation between the degrees of FFLS and GFA. Our results imply that the degrees of FFLS could serve as a measure of the GFA, providing new approach to characterize the GFA for the design of amorphous composite materials. More importantly, our results manifest that sputtering conditions greatly affect the local atomic structures and consequential properties. This result could be extended to other glassy materials as the universality of FFLS for short-range order structure in amorphous. Our study might be useful in optimizing sputtering conditions in real experiments, as well as promising implications in material design of advanced glassy materials.

Supplementary Materials: The following are available online at http:/ /www.mdpi.com/1996-1944/11/12/2548/s1, Table S1: The four nearest neighbor distances in $\mathrm{Zr}$ and $\mathrm{Cu}$ bulk crystals, lattice constants for $\mathrm{Zr}$ and $\mathrm{Cu}$ are respectively $\mathrm{a}_{\mathrm{Zr}}=3.23 \AA, \mathrm{c}_{\mathrm{Zr}}=5.15 \AA$ and $\mathrm{a}_{\mathrm{Cu}}=3.61 \AA$., Table S2: Number of various Voronoi polyhedrons in $\mathrm{Zr}_{\mathrm{x}} \mathrm{Cu} 100-\mathrm{x}(\mathrm{x}=90,70,50)$ under middle energy, Figure S1: Distribution and proportion of typical Voronoi polyhedrons (VPs) in Zr70Cu30 amorphous films under three energies. The left side is FCC-like structure, with ICOS and DICOS in the middle, and other high-content polyhedron on the right.

Author Contributions: Conceptualization, L.X. and Q.P.; methodology, Q.Q.; formal analysis, L.X.; investigation, H.A.; writing—original draft preparation, H.A.; writing—review and editing, L.X. and Q.Q; visualization, Y.Z.; supervision, Q.P and Y.Z.; funding acquisition, L.X.

Funding: The authors are grateful for the financial support provided by the Fundamental Research Funds for the Central Universities (FRF-TP-16-044A1 and FRF-GF-17-B18) and National Natural Science Foundation of China (21703007 and 51375041).

Conflicts of Interest: The authors declare no conflict of interest.

\section{References}

1. Wang, W.H. The elastic properties, elastic models and elastic perspectives of metallic glasses. Prog. Mater. Sci. 2012, 57, 487-656. [CrossRef]

2. Si, J.; Mei, J.; Wang, R.; Chen, X.; Hui, X. Fe-B-Si-Zr bulk metallic glasses with ultrahigh compressive strength and excellent soft magnetic properties. Mater. Lett. 2016, 181, 282-284. [CrossRef]

3. Niu, B.; Sun, M.H.; Wang, D.; Wang, L.N. Thermoplasticity of $\mathrm{Cu}_{45} \mathrm{Zr}_{42.55} \mathrm{Y}_{3.45} \mathrm{~A}_{19}$ metallic glass. Mater. Heat. Treat 2010, 8, 6-9.

4. Liao, G.; Long, Z.; Zhao, M.; Zhong, M.; Liu, W.; Chai, W. Serrated flow behavior in a Pd-based bulk metallic glass under nanoindentation. J. Non-Cryst. Solids 2017, 460, 47-53. [CrossRef]

5. Mattern, N. Structure Formation in Metallic Glasses. Available online: http://www.ww.tu-freiberg.de/mk/ bht/Abstracts / mattern.pdf (accessed on 13 December 2018).

6. Masumoto, T. Recent progress of amorphous metallic materials. Mater. Sci. Eng. A 1994, 179-180, 8-16. [CrossRef]

7. Laws, K.J.; Miracle, D.B.; Ferry, M. A predictive structural model for bulk metallic glasses. Nat. Commun. 2015, 6, 8123. [CrossRef]

8. Cheng, Y.Q.; Ma, E. Atomic-level structure and structure-property relationship in metallic glasses. Prog. Mater. Sci. 2011, 56, 379-473. [CrossRef]

9. Zeman, P.; Zítek, M.; Zuzjaková, Š.; Čerstvý, R. Amorphous Zr-Cu thin-film alloys with metallic glass behavior. J. Alloys Compd. 2017, 696, 1298-1306. [CrossRef]

10. Musil, J.; Daniel, R. Structure and mechanical properties of magnetron sputtered $\mathrm{Zr}-\mathrm{Ti}-\mathrm{Cu}-\mathrm{N}$ films. Surf. Coat. Technol. 2003, 166, 243-253. [CrossRef]

11. Eckert, J.; Das, J.; Kim, K.B.; Baier, F.; Tang, M.B.; Wang, W.H.; Zhang, Z.F. High strength ductile Cu-base metallic glass. Intermetallics 2006, 14, 876-881. [CrossRef] 
12. Xu, D.; Lohwongwatana, B.; Duan, G.; Johnson, W.; Garland, C. Bulk metallic glass formation in binary Cu-rich alloy series- $\mathrm{Cu}_{100-\mathrm{x}} \mathrm{Zr}_{\mathrm{x}}\left(\mathrm{x}=34,36,38.2,40\right.$ at \%) and mechanical properties of bulk $\mathrm{Cu}_{64} \mathrm{Zr}_{36}$ glass. Acta Mater. 2004, 52, 2621-2624. [CrossRef]

13. Karpe, N.; Bøttiger, J.; Krog, J.P.; Nordström, A.; Rapp, Ö. Influence of deposition conditions and ion irradiation on thin films of amorphous Cu-Zr superconductors. Thin Solid Films 1996, 275, 82-86. [CrossRef]

14. Dudonis, J.; Bručas, R.; Miniotas, A. Synthesis of amorphous $\mathrm{Zr-Cu}$ alloys by magnetron co-sputtering. Thin Solid Films 1996, 275, 164-167. [CrossRef]

15. Apreutesei, M.; Djemia, P.; Belliard, L.; Abadias, G.; Esnouf, C.; Billard, A.; Steyer, P. Structural-elastic relationships of $\mathrm{Zr}-\mathrm{TL}(\mathrm{TL}=\mathrm{Cu}, \mathrm{Co}, \mathrm{Ni})$ thin films metallic glasses. J. Alloys Compd. 2017, 707, 126-131. [CrossRef]

16. Aji, D.P.B.; Hirata, A.; Zhu, F.; Pan, L.; Reddy, K.M.; Song, S.; Liu, Y.; Fujita, T.; Kohara, S.; Chen, M. Ultrastrong and Ultrastable Metallic Glass. Available online: https:/ / arxiv.org/ftp/arxiv/papers/1306/ 1306.1575.pdf (accessed on 13 December 2018).

17. Xu, B.; Falk, M.L.; Li, J.F.; Kong, L.T. Predicting Shear Transformation Events in Metallic Glasses. Phys. Rev. Lett. 2018, 120, 125503. [CrossRef]

18. Peng, Q.; Meng, F.; Yang, Y.; Lu, C.; Deng, H.; Wang, L.; De, S.; Gao, F. Shockwave generates $<100>$ dislocation loops in bcc iron. Nat. Commun. 2018, 9, 4880. [CrossRef] [PubMed]

19. Utz, M.; Peng, Q.; Nandagopal, M. Athermal simulation of plastic deformation in amorphous solids at constant pressure. J. Polym. Sci. B Polym. Phys. 2004, 42, 2057-2065.

20. Sha, Z.D.; Zhang, Y.W.; Feng, Y.P.; Li, Y. Molecular dynamics studies of short to medium range order in Cu64Zr36 metallic glass. J. Alloys Compd. 2011, 509, 8319-8322. [CrossRef]

21. Wu, T.W.; Feng, S.D.; Qi, L.; Gao, W.; Ma, M.Z.; Zhang, X.Y.; Li, G.; Jing, Q.; Liu, R.P. The compressive behaviour after crystallisation in $\mathrm{Zr} 85 \mathrm{Cu} 15$ metallic glasses studied by molecular dynamics simulations. J. Non-Cryst. Solids 2017, 468, 41-45. [CrossRef]

22. Yang, G.J.; Xu, B.; Kong, L.T.; Li, J.F.; Zhao, S. Size effects in Cu 50 Zr 50 metallic glass films revealed by molecular dynamics simulations. J. Alloys Compd. 2016, 688, 88-95. [CrossRef]

23. Xie, L.; Brault, P.; Bauchire, J.-M.; Thomann, A.-L.; Bedra, L. Molecular dynamics simulations of clusters and thin film growth in the context of plasma sputtering deposition. J. Phys. D Appl. Phys. 2014, 47, 224004. [CrossRef]

24. Sha, Z.; Feng, Y.; Li, Y. Statistical composition-structure-property correlation and glass-forming ability based on the full icosahedra in Cu-Zr metallic glasses. Appl. Phys. Lett. 2010, 96, 061903. [CrossRef]

25. Hajlaoui, K.; Alsaleh, N.; Alrasheedi, N.H.; Yavari, A.R. Coalescence and subsequent twinning of nanocrystals during deformation of CuZr-based metallic glasses: The grain size effect. J. Non-Cryst. Solids 2017, 464, 39-43. [CrossRef]

26. Almyras, G.A.; Lekka, C.E.; Mattern, N.; Evangelakis, G.A. On the microstructure of the $\mathrm{Cu}_{65} \mathrm{Zr}_{35}$ and $\mathrm{Cu}_{35} \mathrm{Zr}_{65}$ metallic glasses. Scr. Mater. 2010, 62, 33-36. [CrossRef]

27. Tripathi, M.K.; Chattopadhyay, P.P.; Ganguly, S. A predictable glass forming ability expression by statistical learning and evolutionary intelligence. Intermetallics 2017, 90, 9-15. [CrossRef]

28. Turchanin, A.A.; Tomilin, I.A.; Turchanin, M.A.; Belokonenko, I.V.; Agraval, P.G. Enthalpies of formation of liquid and amorphous $\mathrm{Cu}-\mathrm{Zr}$ alloys. J. Non-Cryst. Solids 1999, 250-252, 582-585. [CrossRef]

29. Yang, X.; Zhang, Y. Prediction of high-entropy stabilized solid-solution in multi-component alloys. Mater. Chem. Phys. 2012, 132, 233-238. [CrossRef]

30. Hu, Y.C.; Li, F.X.; Li, M.Z.; Bai, H.Y.; Wang, W.H. Five-fold symmetry as indicator of dynamic arrest in metallic glass-forming liquids. Nat. Commun. 2015, 6, 8310. [CrossRef] [PubMed]

31. Lü, Y.J.; Bi, Q.L.; Huang, H.S.; Pang, H.H. Role of fivefold symmetry in the dynamical slowing down of metallic glass-forming liquids. Phys. Rev. B 2017, 96, 064301. [CrossRef]

32. Plimpton, S. Fast Parallel Algorithms for Short-Range Molecular Dynamics. J. Comput. Phys. 1995, 117, 1-19. [CrossRef]

33. Stukowski, A. Visualization and analysis of atomistic simulation data with OVITO-the Open Visualization Tool. Model. Simul. Mater. Sci. Eng. 2010, 18, 015012. [CrossRef]

34. Berendsen, H.J.C.; Postma, J.P.M.; van Gunsteren, W.F.; DiNola, A.; Haak, J.R. Molecular dynamics with coupling to an external bath. J. Chem. Phys. 1984, 81, 3684-3690. [CrossRef] 
35. Daw, M.S.; Baskes, M.I. Embedded-atom method: Derivation and application to impurities, surfaces, and other defects in metals. Phys. Rev. B 1984, 29, 6443-6453. [CrossRef]

36. Graves, D.B.; Brault, P. Molecular dynamics for low temperature plasma-surface interaction studies. J. Phys. D Appl. Phys. 2009, 42, 194011. [CrossRef]

37. Zhen, S.; Davies, G.J. Calculation of the Lennard-Jones $n-m$ potential energy parameters for metals. Phys. Status Solid 1983, 78, 595-605. [CrossRef]

38. Xie, L.; Brault, P.; Thomann, A.-L.; Bedra, L. Molecular dynamic simulation of binary $\mathrm{Zr}_{\mathrm{x}} \mathrm{Cu}_{100-\mathrm{x}}$ metallic glass thin film growth. Appl. Surf. Sci. 2013, 274, 164-170. [CrossRef]

39. Finney, J.L. Modelling the structures of amorphous metals and alloys. Nature 1977, 266, 309-314. [CrossRef]

40. Wu, Z.W.; Li, M.Z.; Wang, W.H.; Liu, K.X. Hidden topological order and its correlation with glass-forming ability in metallic glasses. Nat. Commun. 2015, 6, 6035. [CrossRef]

41. Liu, X.J.; Xu, Y.; Lu, Z.P.; Hui, X.; Chen, G.L.; Zheng, G.P.; Liu, C.T. Atomic packing symmetry in the metallic liquid and glass states. Acta Mater. 2011, 59, 6480-6488. [CrossRef]

42. Zhang, W.; Liaw, P.K.; Zhang, Y. Science and technology in high-entropy alloys. Sci. China Mater. 2018, 61, 2-22. [CrossRef]

43. Li, M.Z.; Peng, H.L.; Hu, Y.C.; Li, F.X.; Zhang, H.P.; Wang, W.H. Five-fold local symmetry in metallic liquids and glasses. Chin. Phys. B 2017, 26, 016104. [CrossRef]

44. Spaepen, F. Condensed-matter science: Five-fold symmetry in liquids. Nature 2000, 408, 781-782. [CrossRef] [PubMed]

(C) 2018 by the authors. Licensee MDPI, Basel, Switzerland. This article is an open access article distributed under the terms and conditions of the Creative Commons Attribution (CC BY) license (http:/ / creativecommons.org/licenses/by/4.0/). 